\title{
events guide
}

\section{Oded Rechavi Setting up the Woodstock of biology}

Molecular biologist Oded Rechavi uses nematodes to investigate epigenetic inheritance at Tel Aviv University in Israel. Rechavi has organized what he calls the Woodstock of Biology, a free conference for scientists he enjoys interacting with on Twitter. It will take place on the Tel Aviv University campus from 13 to 14 February 2020, a few days before an experimental-biology conference in Eilat. At the Woodstock conference, each attendee will present a short talk outlining new, unpublished work using two slides simultaneously posted on Twitter; questions and answers will follow online.

How did you come up with the idea for this conference?

It was midnight on a Friday in June this year. I had some nice exchanges with scientists whom I know only from Twitter. The biology community on Twitter is very supportive and progressive. I said to myself that it would be nice to meet these people and form a real community instead of a virtual one. So I tweeted that I would be happy to organize a conference for these scientists to meet in person. I woke up in the morning and I saw that there were hundreds of responses. People kept tweeting, retweeting, "sign me up." So we built a website and close to 200 people signed up.

\section{Why is Twitter useful for science?}

Twitter is amazing. You learn everything in real time, as it happens. People read your paper; they react fast. Specialists respond, and you can reply to them. It's all online and open. It's a revolution in the way that we spread information about science.

\section{Why is the Woodstock of Biology} important?

I'm hoping to reproduce that informal, fun, real-time involvement with peers and non-specialists that you find on Twitter and make it work in a conference format. The science community on Twitter is big, but it's not always clear how it overlaps with the real science community. This meeting is the first time, to my knowledge, that we're joining the two worlds, and the potential is that some of the good stuff inside the Twitter science

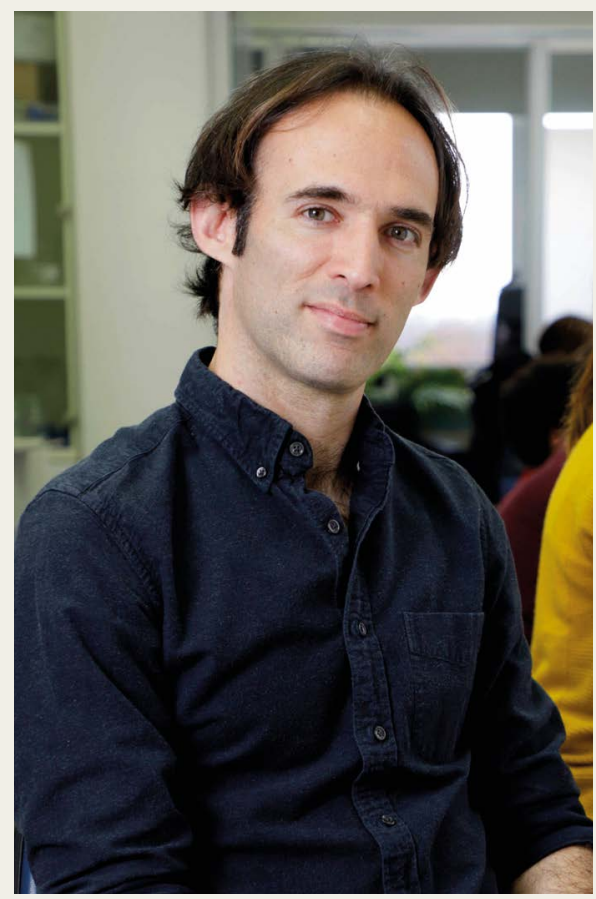

community will penetrate the real science world and influence it.

Why did you call it the Woodstock of Biology? It was coined by Shai Biran - an acquaintance who works at the biotech consultancy firm MacDougall in Natick, Massachusetts. It symbolizes what the original Woodstock music festival symbolized: counterculture and freedom from social conventions, and peace and music too.

\section{How will this conference be different from all} other scientific conferences?

We want it to be collaborative and nonhierarchical, without a moderator. People who are not present at the conference can also respond online with questions. We'll have walk-up songs for each speaker, which tells us a little bit about their personalities.

\section{How does this meeting help scientists?} When you go to some conferences, you hear things you already know. People are afraid of being scooped, so avoid speaking about completely new things that are far away from publication. But if you want conferences to stay relevant, you need to encourage speakers to talk about new stuff. I think because so many tweeters and science communicators will be at the conference looking at the work, it doesn't give anyone else the chance to scoop work without being caught - in that way, presenting at the conference will be like publishing a preprint.

\section{What do you hope to achieve in this conference?}

I hope to get some collaborations going for myself and others. I'm hopeful that it will be a model of how conferences should be: when you do something in a fun and friendly way, it improves the chances that people will be friendlier and enjoy themselves, and not be defensive or competitive.

Which speakers have signed up? One keynote speaker is Dan Shechtman at the Technion, Israel's Institute of Technology in Haifa, who won the 2011 Nobel Prize in Chemistry. Another is neurobiologist Piali Sengupta at Brandeis University in Waltham, Massachusetts. The third is systems biologist Uri Alon at the Weizmann Institute of Science in Rehovot, Israel. We will have PhD students talking alongside a Nobel prizewinner, and will cover a range of disciplines: from ecology and molecular biology to neuroscience and philosophy of science.

What are some of the advantages for early-career researchers attending this conference?

In a really practical way they have an opportunity to talk about their research, as equals, next to really prominent scientists from different fields. I think it will help them to find positions, get connected, help them to tweet their stories and increase their visibility.

What advice would you give to others organizing similar conferences? We should let young people talk, and not just invite the same people over and over. I think that the format we are inventing could also be mimicked. I would be happy to have walk-up songs at every conference. Making conferences fun is something I think will help science.

\section{Interview by Josie Glausiusz}

This interview has been edited for length and clarity. 